\title{
Novel use of balloon tamponade saves a patient with uterine inversion in severe shock
}

\author{
Sumitra Yadav, Anjali Malhotra*
}

Department of Obstetrics and Gynecology, MGMMC and MYH, Indore, Madhya Pradesh, India

Received: 27 August 2017

Revised: 23 October 2017

Accepted: 26 October 2017

\author{
*Correspondence: \\ Dr. Anjali Malhotra, \\ E-mail: anjalimalhotra.mbbs@gmail.com
}

Copyright: $\odot$ the author(s), publisher and licensee Medip Academy. This is an open-access article distributed under the terms of the Creative Commons Attribution Non-Commercial License, which permits unrestricted non-commercial use, distribution, and reproduction in any medium, provided the original work is properly cited.

\begin{abstract}
A patient with G1P0 status 38 weeks pregnancy with pain with no high risk delivered at PHC, Hatod, Madhya Pradesh (India). She delivered a male baby by spontaneous vaginal delivery of $3.1 \mathrm{~kg}$. All of sudden after $2^{\text {nd }}$ stage of labour, her $3^{\text {rd }}$ stage of labour was eventful. Placenta did not come out spontaneously so controlled cord traction was given by the ANM over the PHC. She was given intramuscular oxytocin 5 IU. She did the traction with proper care but inspite of that while doing so placenta got separated but there was complete uterine inversion. ANM herself tried to reposit the uterus but could not do so. So ANM immediately referred her from PHC to MYH, Indore, Madhya Pradesh (India).
\end{abstract}

Keywords: Balloon tamponade, Condom catheter, Intramuscular oxytocin, Uterine inversion

\section{INTRODUCTION}

Uterine inversion is the folding of the fundus into the uterine cavity in varying degrees. In first degree inversion, the wall extends as far as, but not through, the cervix. In second degree inversion, the fundus prolapses through the cervix but not out of the vaginal opening. Third degree inversion involves prolapse of the fundus outside of the vagina, and fourth-degree prolapse is the complete prolapse of both uterus and vagina. Acute inversion occurs within the first 24 hours after delivery; subacute refers to inversion between 24 hours and 30 days after delivery, and chronic inversion is inversion after 30 days. ${ }^{1}$

It can also be classified into complete and incomplete inversion. Complete inversion occurs when the inverted uterus has passed completely through the cervix to lie within the vagina or less often, outside the introitus. Incomplete inversion occurs when the fundus of the uterus has turned inside out, rather like the toe of a sock, but the inverted fundus has not descended through the cervix. $^{2}$ For the uterus to be inverted it must be relaxed and this, along with fundal insertion of the placenta, are important pre-disposing conditions. Additional factors are mismanagement of the third stage of labor involving fundal pressure and or cord traction before placental separation and while the uterus is still relaxed. Abnormally short cord or functionally shortened by being wrapped around the fetal body is a rare cause. Sudden rise in intra-abdominal pressure, morbid adherence of a fundally implanted placenta, manual removal of placenta during the caesarean section-this can occur with those who routinely undertake manual removal of placenta at the time of caesarean section before the uterus has contracted. While pulling the cord the placenta, which is still attached to the fundus of the uterus, so as when placenta is withdrawn so too is the fundus of the uterus; thus inversion occurs. ${ }^{2}$ Even connective tissue disorders can pre-dispose to acute uterine inversion. ${ }^{3}$ Diagnosis 
may be obvious and dramatic with a large boggy mass appearing at the introitus. The other signs and symptoms are severe and sustained hypo gastric pain in the third stage of labor, shock and absence of uterus abdominally in complete inversion. Shock is out of proportion with apparent blood loss being a neurogenic shock, due to stretching of the infudibulopelvic and round ligament, ovaries and associated nerves being pulled into the crater of the inversion that provides a strong vasovagal stimulus. Thus, the woman often becomes pallid and sweaty, with profound hypotension with bradycardia and may even, on rare occasions, have a cardiac arrest. Within a short time, in the majority of cases, there is also marked haemorrhage and hypovolemic shock. ${ }^{4,5}$

\section{CASE REPORT}

A patient with G1P0 status 38 weeks pregnancy with pain with no high risk delivered at PHC, Hatod, Indore Madhya Pradesh (India). She delivered a male baby by spontaneous vaginal delivery of $3.1 \mathrm{~kg}$ on $21 / 02 / 17$ at 9 am. After her uneventful $2^{\text {nd }}$ stage of labour, her $3^{\text {rd }}$ stage of labor was eventful. Placenta did not come out spontaneously so controlled cord traction was given by the ANM over the PHC. She was given intramuscular oxytocin $5 \mathrm{IU}$. She did the traction with proper care but inspite of that while doing so placenta got separated but there was complete uterine inversion. ANM herself tried to reposit the uterus but could not do so. So ANM immediately referred her from PHC to MGMMC and MYH, Indore, Madhya Pradesh (India). The patient presented to our hospital with postnatal Day 1 with uterine inversion with moderate anemia with shock on $21 / 02 / 17$ in emergency hours at around 3pm. Patient had complaints of something coming out of vagina and bleeding per vaginally since delivery. The patient came in shock with poor general condition, pulse being feeble with Heart rate 140/minute and tachypnea with systolic BP $80 \mathrm{mmHg}$ chest clear pedal edema absent. On per speculum examination uterus was lying outside, coming out through introitus i.e. complete uterine inversion.
Uterus was flabby and atonic in consistency. The initial estimated blood loss was nearly $500 \mathrm{ml}$. We secured intravenous access with 2 large bore cannulas and infused 1-unit haystarch $500 \mathrm{ml}$ and started inotropic support and 1 unit packed cell volume. In the meanwhile, I tried to manually reposit the uterus inside the pelvic cavity with hand and could possibly do it but after removing my hand out the pelvic cavity uterus again got inverted so I kept my hand inside and gave bimanual uterine massage and infused 40 units oxytocin stat in $500 \mathrm{ml}$ NS drip after starting her noradrenaline and dopamine support. I shifted the patient to ICU. Anesthetist was called urgently. I catheterized her. I even gave her Methergin $0.2 \mathrm{mg}$ and also gave Prostadin $125 \mathrm{mcg}$ stat. In the meanwhile, I introduced $\mathrm{CG}$ balloon condom catheter using $18 \mathrm{~F}$ foley's catheter in the uterine cavity with sponge holding forceps and kept it there until I inflate (it with normal saline). We inflated the balloon to nearly $450-500 \mathrm{ml}$. Vaginal packing was done with 3 packs in situ.

Her strict vital charting was done, and it was observed that at around $6 \mathrm{pm}$ her vitals improved with GC average and BP $100 / 70$ which gradually improved to $120 / 80$ over a period of 6 hours. Inotropic support was continued till 18 hours and stopped later.

Later on, the uterine cavity started contracting after 40-45 minutes and bleeding subsequently decreased. Earlier it was profuse but as soon as condom was inflated it decreased and hemostasis was achieved. Patient subsequently improved, and her Blood pressure improved from $90 / 60$ to $110 / 70$. Patient was stable over the period of 5-6 hours. We kept oxytocin drip on flow and tapered it on next day to 20-unit oxytocin. We kept the condom catheter for 2 days and removed it on 23/02/17. The oxytocin 20 unit in $500 \mathrm{ml}$ RL drip was there on flow during removal of condom catheter and uterus was contracted and did not become atonic later. Patient was managed in the tertiary care centre with the basic low cost-effective method.

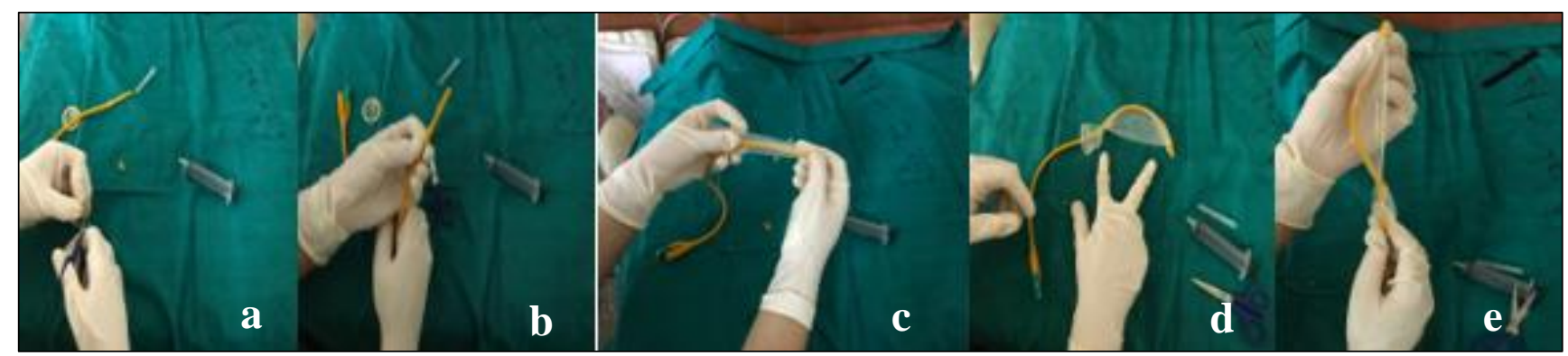

(a) cutting two rings from the drainage tube of foley's catheter; (b) Excision of the bulb of catheter subsequent to infiation with 2-5 ml of air; (c) Rolling of condom over catheter; (d) Tying condom to catheter using the rings twice around both the ends of condom leaving $1.5-2 \mathrm{~cm}$. of condom on either end; (e) Excision of the tip of Foley's along with the blind end of condom together $0.5 \mathrm{~cm}$. away from the tied ring. Leaving both the rings with CG Balloon.

Figure 1: Formation of condom catheter 


\section{DISCUSSION}

A similar study was seen using condom catheter. In their case, the risk factors were a forced traction on the cord while the placenta was not detached from the myometrium and the delivery performed by ANM. With the introduction of AMTSL, the incidence of uterine inversion may increase if the obstetrician does not respect the conditions of the directed delivery including controlled cord traction and proscription of uterine expression to prevent this complication.

The diagnosis is primarily clinical with hemorrhage, pelvic pain and cardiovascular collapse which are the main warning signs. The uterine inversion stage III is visible from the perineal inspection with a fundus externalized to the vulva as a fleshy mass bloody.

The treatment must be immediate and based on three main points: correction of cardiovascular collapse, intraabdominal replacement of the uterus and uterine atony correction. Literature data recommends first a manual reduction by simply reversing taxis which consists to push the fundus in order to replace it or the Johnson's method which consists of a pressure on the vaginal culde-sac by vaginal fingers and the bottom by the palm of the hand. ${ }^{7}$

In case of failure of the manual repositioning, other methods are described: hydrostatic methods which consist in filling the vagina with saline in sealing the vagina either manually (O'Sullivan) or by using a suction cup (Ogueh) - the uterine packing - surgical correction by high way by the Huntington technique or Haultain or vaginally with the technique of Spinelli - hysterectomy hemostasis remains the gold standard in case of persistent bleeding but is exceptional. ${ }^{7,9,11,12}$

More recently the use of balloons such as Rusch or Bakri have been described in the literature as the re-inversion prevention method within two hours following initial reintegration. ${ }^{10,13-16}$ They are associated with fewer complications (infection and necrosis uterine) compared to uterine sutures. In this case, despite uterine massage and Oxytocin infusion, there was a persistent atony. The use of intrauterine balloon tamponade allowed us to stop the bleeding and prevent uterine re-inversion. This balloon, easy to use and low cost, has the advantage of being available in our resource-limited countries. Whatever the technique used, antibiotic therapy should be systematic to avoid the risk of postpartum endometritis.

\section{CONCLUSION}

The basic purpose of this case report is to improve prognosis in the primary health care center where uterine inversion seems to be catastrophic, this condom catheter can aptly help in the management of third stage complications. Its role in atonic $\mathrm{PPH}$ is approved but it played immense role in uterine inversion too. Hence it can be highly helpful in low resource settings.

Funding: No funding sources

Conflict of interest: None declared

Ethical approval: Not required

\section{REFERENCES}

1. Belfort MA, Dildy GA. Postpartum hemorrhage and other problems of the third stage. In: James DK, Steer PJ, Weiner CP, eds. High risk Pregnancy: Management options. $4^{\text {th }}$ edition. Saunders Elsevier; 2011:1283-1312.

2. Studziński Z, Branicka D. Acute complete uterine inversion: Case report. Ginekol Pol. 2001;72:881-4.

3. Baskett TF, Calder AA, Arulkumaran S. Acute uterine inversion. In: Green E, eds. Munro Kerr's, operative obstetrics. $11^{\text {th }}$ ed. Amsterdam: Saunders Elsevier; 2007:243-9.

4. Quinn RJ, Mukerjee B. Spontaneous uterine inversion in association with Marfan's syndrome. Aust N Z J Obstet Gynaecol. 1982;22:163-4.

5. Wendel PJ, Cox SM. Emergent obstetric management of uterine inversion. Obstet Gynecol Clin North Am. 1995;22:261-74.

6. Rachagan SP, Sivanesaratnam V, Kok KP, Raman S. Acute puerperal inversion of the uterus. An obstetric emergency. Aust N Z J Obstet Gynaecol. 1988;28:29-32.

7. Mishra N, Agrawal S, Gulabani K, Shrivastava C. Use of an innovative condom balloon tamponade in postpartum hemorrhage: a report. The Federation of Obstetric and Gynecological Societies of India. 2016;66(1). Available at http://www.jogi.co.in/jan_feb_16/13_it.html

8. Keriakos R, Chaudhuri SR. Managing major postpartum haemorrhage following acute uterine inversion with Rusch balloon catheter case rep. Crit Care. 2011;2011:541479.

9. Majd HS, Pilsniak A, Reginald PW. Recurrent uterine inversion: a novel treatment approach using SOS Bakri balloon. British $\mathrm{J}$ of Obst and Gyn. 2009;116(7):999-1001.

10. Botolahy ZA, Rakotovao M, Randriambololona DMA, Randriamahavonjy R, Rakotovao A. Hery: uterine inversion: an unusual cause of hemorrhage from deliverance. Rev Trop Chirur. 2008;2:22-3.

11. Hostetler DR, Bosworth MF. Uterine inversion: a life-threatening obstetric emergency. J Am Board of Family Practice. 2000;13(2):120-3.

12. Tan KH, Luddin NSY. Hydrostatic reduction of acute uterine inversion. Int $\mathbf{J}$ Gyn Obst. 2005;91(1):63-4.

13. Jerbi M, Iraqui Y, Jacob J, Truc B. Inversion acute puerperal uterine: about two cases. Gyn Obst Fert. 2004;32:224-7.

14. Irani S, Jordan J. Management of uterine. Cur Obst Gyn. 1997;7:232-5. 
15. Mbuagbaw L, Mbah OP. Complete acute uterine inversion. J Obst Gyn Res. 2011;37(7):897-900.

16. Rossolymos C, Peittsidis P, Anastasiadis A, Venizelou $H$. The use of Bakri balloon in management of severe post-partum hemorrhage due to neglected uterine inversion in a HIV positive patiente. Int J Gynecol Obstet. 2012;119S3:531S867.
17. Uzoma A, Ola B. Complete uterine inversion managed with a Rusch balloon catheter. J Med Cases. 2010;1(1):8-9.

Cite this article as: Yadav S, Malhotra A. Novel use of balloon tamponade saves a patient with uterine inversion in severe shock. Int J Reprod Contracept Obstet Gynecol 2017;6:5638-41. 